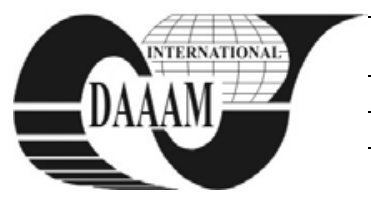

Annals of DAAAM for 2011 \& Proceedings of the 22nd International DAAAM Symposium, Volume 22, No. 1, ISSN 1726-9679 ISBN 978-3-901509-83-4, Editor B. Katalinic, Published by DAAAM International, Vienna, Austria, EU, 2011 Make Harmony between Technology and Nature, and Your Mind will Fly Free as a Bird Annals \& Proceedings of DAAAM International 2011

\title{
RESIDUAL STRESSES AND THE ULTRASONIC QUENCHING
}

\author{
BANCESCU, N[icolai]; DULUCHEANU, C[onstantin] \& SEVERIN, T[raian] - L[ucian]
}

\begin{abstract}
In this article, the authors present a possible use of quenching in ultrasonic field for bearing steels. The classic quenching determine in the structure steel stresses that may exceed the limit of plasticity of the steel and which cause deformation of the products. The ultrasonic quenching reduces stresses level and ensures high dimensional stability.

Key words: quenching, ultrasonic field, bearing steel, residual stress
\end{abstract}

\section{INTRODUCTION}

The cooling in liquid medium with low point of vaporization in quenching steel causes the formation of residual stresses witch in many cases are added together with operating tensions and produce deformation or breaking when the product exceeds the yield strength or breaking the material. After the origin of these tensions are divided into two groups:

- $\quad$ thermal stresses, due to cooling caused by heat shock;

- $\quad$ structural tension, caused by differences in specific volume of austenite and martensite formed by cooling.

The highest values of thermal stresses are responsible, in most cases, relatively by large amounts of deformation produces on quenching.

During quenching, cooling products through four successive stages in time, namely: subcooling strong, calefaction, boiling violent and boiling quiet. The analysis of the quenching cooling process shows that the most dangerous stage is represented by calefaction, when a fracture occurs in the evolution of cooling rate and the product is subjected to significant thermal shock. The practice of heat treatments to reduce the unfavorable calefaction effect is achieved by shaking fluid or product during the cooling.

The interest in using ultrasound in the practice of heat treatments is recent and started with research of Palme, Bulat and others on the influence of ultrasound on the cooling capacity of environments to quench steel (Abaskina, 1990) (Abramov, 1984) (Bancescu, 1995).

Experiments have shown that applying an ultrasonic field cooling fluid increases the cooling capacity of the physicochemical environments, eliminating at the same time, one of the most dangerous stages of cooling, namely calefaction. Vibration with ultrasonic frequencies of the fluid immediately surrounding the product for cooling produces vapor bubbles implode which tend to form on its surface, restoring the exchange of heat, close to the initial intensity and eliminates thermal shock what causing deformations and cracks the quenching steels (Abaskina, 1990) (Abramov, 1984).

Radiation conditions of elastic vibration frequency and ultrasonic sound in a liquid are more favorable than in a gaseous environment. Average acoustic power radiated from a vibrating surface, with sizes larger than the wavelength, has the value (Amza, 2006):

$$
P=\left(10^{-7} \cdot S \cdot \rho C \cdot V^{2}\right) / 2
$$

where: $\mathrm{S}$ is the surface area of the vibrator, $\rho \mathrm{C}$ - sound environmental resistance and $\mathrm{V}$ - the speed of vibration of the vibrator surface.

Modern treatment plants working with ultrasonic frequencies between 40 and $90 \mathrm{kHz}$. Generally not recommended to fall below $40 \mathrm{kHz}$ ultrasound frequency, because the first subharmonic is in the audible range and noise can become harmful to the operator. Upper limit frequency (90 $\mathrm{kHz}$ ) is not exceeded for technical reasons (efficiency of these facilities decreases with increasing work rate) (Amza, 2006). In terms of sound power, is working normally, with powers of $2 \ldots .3 \mathrm{~W} / \mathrm{cm}^{2}$, cavitation limit, to ensure maximum power and protect cooler elements. Ciacin, Pogodnoi-Alekseev and Eremenin research pointed out that ultrasound causes a substantial change at tempering in the steel structure, both in terms of hardness as well as other microstructural parameters (size of mosaic blocks, the percentage of residual austenite, residual stresses, density dislocations, etc..), confirmed by modern analytical methods such as X-ray (Abaskina, 1990) (Abramov, 1984) (Amza, 2006). The influence of ultrasonic field on martensitic transformation in steel can be explained theoretically using the mathematical expression of the transformation actuating force (Birount, 1977):

$$
\Delta \mathrm{F}_{\alpha^{\prime} \text { real }}=\mathrm{F}_{\alpha, \text { real }}-\mathrm{F}_{\beta}=\mathrm{F}_{\alpha},+\Delta \mathrm{U}_{\mathrm{e}}-\mathrm{F}_{\beta}
$$

Since in the martensitic transformation $\Delta \mathrm{U}_{\mathrm{e}}$ positive term increases faster than the negative difference $\left|F_{\alpha},-F_{\beta}\right|$, at a time actuating force $\Delta \mathrm{F}_{\alpha}$,real becomes null and processing

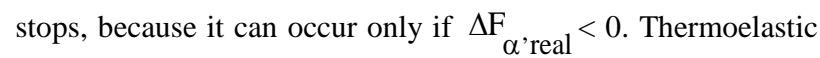
equilibrium can move in one direction or another, depending on temperature (Birount, 1977). The application of ultrasonic field is actually performing an additional energy, in turn, changes this balance. This energy field must be large enough (2...3 $\left.\mathrm{W} / \mathrm{cm}^{2}\right)$.

\section{EXPERIMENTAL DETAILS}

Research on ultrasonic quenching of steel bearings were initiated in the Heat Treatment Laboratory of the Faculty of Mechanical Engineering, Mechatronics and Management from the "Stefan cel Mare" University of Suceava, Romania, since 1990 (Bancescu, 1995). To this end we used a cooler with tank capacity of $40 \mathrm{dm}^{3}$, referred to the bottom with a piezoelectric transmitter with an output of $200 \mathrm{~W}$ and the resonant frequency of $40.4 \mathrm{kHz}$. The ultrasonor (US) generator, designed and implemented within the faculty, has $300 \mathrm{~W}$ output, allows the adjustment of the working frequency $20 . . .45 \mathrm{kHz}$ and allows adjustment of output power in 5 steps (Bancescu, 1995). During the research has followed the influence of US quenching on the structure, hardness, residual stress level, time and dimensional stability on the fatigue behavior under Hertzian type contacts 
elastohidrodinamic under lubrication.

The paper will be presented only experimental results on US quenching influence on the level of residual stress after quenching. To determine the residual stresses were used ring samples from RUL1, with dimensions: $\mathrm{d}=20 \pm 0.5 \mathrm{~mm}, \mathrm{D}=30 \pm 0.010 \mathrm{~mm}$, $\mathrm{h}$ $=10 \mathrm{~mm}$ and roughness $\mathrm{Ra}=0.6 \mu \mathrm{m}$. Chemical composition, determined with a POLIVAC device, is: $1,05 \% \mathrm{C}, 0,37 \% \mathrm{Mn}$, $0,22 \% \mathrm{Si}, 1,50 \% \mathrm{Cr}$.

The heating for quenching was carried out in an electric furnace to $850{ }^{\circ} \mathrm{C}$, the retention time was 40 minutes. As cooling medium was used mineral oil Lubrifin MET 1R type II, recommended for quenching bearing elements. They used two groups of 10 samples each divided into two groups labeled $\mathbf{A}$ and B. Quenching cooling for group A was made classic by mechanical agitation of samples during cooling. Lot $\mathbf{B}$ was cooled in US oil activated with frequency of $40.4 \mathrm{kHz}$ and $\mathrm{I}=4 \mathrm{~W} / \mathrm{dm}^{2}$.

Determination of residual stresses in the surface heat treated rings was made by two methods, namely:

1. Sochs method. Sochs method allows simple determination of the state tension by removing successive layers of material. For this purpose it utilizes anodic dissolution, and the processes used superfinishing or metallography. For measuring deformation can be used as resistive strain gauge method has undeniable advantages in terms of both simplicity and sensitivity of measurements as measurements, especially for small parts. Measuring stick marks are glued tangentially on the workpiece and covered with a protective lacquer. To eliminate the influence of thermal deformations in the electrolysis bath are inserted a piece that is placed identical marks compensating Bancescu, 1995). Amount of material removed by dissolution can be determined by weighing, by measuring or using Faraday's law. By dissolving a layer of a certain thickness on the outer surface of a ring is removed the residual stresses stored in it. It can be considered in this case that the action of external pressure $\mathrm{p}_{\mathrm{e}}$ the ring is deformed. Between strain $\varepsilon$ recorded recorded by strain gauge bridge and radial displacement of a point on the ring $u$ on marks that are stuck there relationship:

$$
\frac{\varepsilon}{2}=\frac{u}{r}
$$

where:

$$
\mathbf{u}=\frac{1-\mu}{E} \cdot \frac{\mathbf{p}_{\mathbf{i}} \cdot \mathbf{R}_{\mathbf{i}}^{2}-\mathbf{p}_{\mathbf{e}} \cdot \mathbf{R}_{\mathbf{e}}^{2}}{\mathbf{R}_{\mathbf{e}}^{2}-\mathbf{R}_{\mathbf{i}}^{2}}+\frac{1+\mu}{\mathbf{E} \cdot \mathbf{r}} \cdot \frac{\left(\mathbf{p}_{\mathbf{i}}-\mathbf{P}_{\mathbf{e}}\right) \cdot \mathbf{R}_{\mathbf{i}}^{2} \cdot \mathbf{R}_{\mathbf{e}}^{2}}{\mathbf{R}_{\mathbf{e}}^{2}-\mathbf{R}_{\mathbf{i}}^{2}}
$$

putting the initial conditions $r=R_{i}$ şi $p_{i}=0$ obtain:

$$
\mathbf{P}_{\mathbf{e}}=\frac{-\varepsilon \cdot \mathbf{E} \cdot\left(\mathbf{R}_{\mathbf{e}}^{2}-\mathbf{R}_{\mathbf{i}}^{2}\right)}{4 \cdot \mathbf{R}_{\mathbf{e}}^{2}}
$$

in which: $\mathrm{p}_{\mathrm{e}}$ - external pressure applied to the ring by the imbalance caused by the tension elimination contained in the dissolved layer; $R_{i}$ - inner radius of the ring; $R_{e}$ - outer radius of the ring; $\mu$ - transverse contraction coefficient of the material, $\mathrm{E}$ - elasticity modulus of the material. Using relations:

$$
\sigma_{r}=\frac{\varepsilon \cdot E}{4} \cdot\left(1-\frac{\mathbf{R}_{i}^{2}}{\mathbf{r}^{2}}\right) \quad \sigma_{t}=\frac{\varepsilon \cdot E}{4} \cdot\left(1+\frac{\mathbf{R}_{i}^{2}}{\mathbf{r}^{2}}\right)
$$

can calculate the voltages on each side of the ring.

2. Diffractometer method. To validate the measurements by Sochs method, parallel measurements were made in the level of residual stress diffractometer method (Gherghies, 1990). Measurements were made on a DRON 3M device at the "Dunarea de Jos” University of Galati, Romania.

\section{EXPERIMENTAL RESULTATS}

The results of experimental measurements are presented in table 1,2 and figure 1 .

\begin{tabular}{|c|c|c|}
\hline \multirow{2}{*}{$\begin{array}{c}\text { Depth "s" } \\
{[\mathrm{mm}]}\end{array}$} & \multicolumn{2}{|c|}{ Residual stresses, [MPa] } \\
\cline { 2 - 3 } & $\begin{array}{c}\text { Quenching } \\
\text { regime } \\
\text { A }\end{array}$ & $\begin{array}{c}\text { Quenching } \\
\text { regime } \\
\text { B }\end{array}$ \\
\hline 0.21 & 171.60 & 66.90 \\
\hline 0.36 & 174.00 & 66.86 \\
\hline 0.49 & 192,50 & 76.80 \\
\hline 0.75 & 245.00 & 83.20 \\
\hline
\end{tabular}

Tab.1. Variation of residual stresses level with depth etermined by the method Sochs

\begin{tabular}{|c|c|}
\hline \multicolumn{2}{|c|}{ Residual stresses, [MPa] } \\
\hline $\begin{array}{c}\text { Quenching regime } \\
\text { A }\end{array}$ & $\begin{array}{c}\text { Quenching regime } \\
\text { B }\end{array}$ \\
\hline 109 & 61 \\
\hline
\end{tabular}

Tab.2. Residual stresses level surface to $0.20 \mathrm{~mm}$, determined with diffractometer DRON 3M (average of 5 determinations)

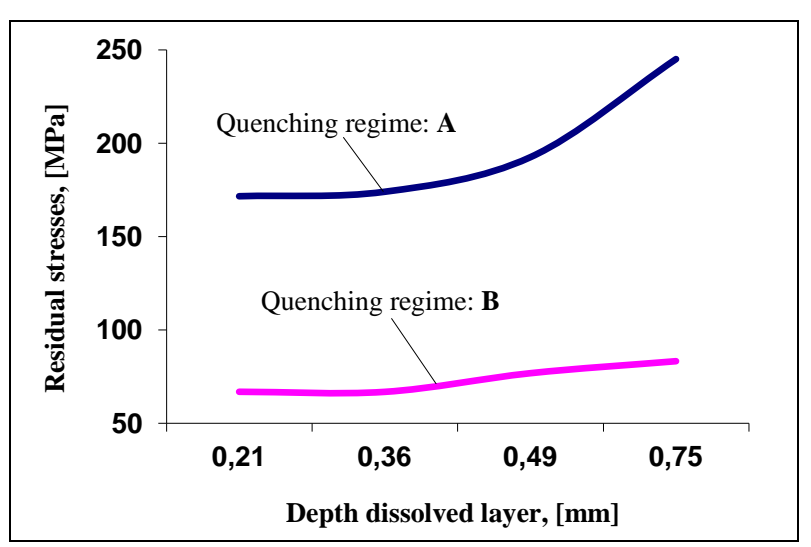

Fig. 1. Variation of residual stresses level with the depth dissolved layer

\section{CONCLUSIONS}

Quenching in ultrasonic (US) field exerts a sensitive influence on the structure and properties of bearing steels. Additional energy contribution due to activation of the cooling US medium influence the kinetics of martensitic transformation quenching. Simultaneously, ultrasonication of cooling fluid, considered incompressible, determine a degree of stress relieving, even during the quenching, as confirmed by experimental measurements, but also the influence in time of subsequent measurements on dimensional stability.

\section{REFERENCES}

Abaskina, I. V. et al., (1990), Soprotivlenie kontactnoi ustalosti poroşkovoi stali SH15, Metallovedenie i termiceskaia obrabotka metallov, nr.8, pp. 56 - 59

Abramov, O. V. (1984), Ulitrazvukovaia obrabotka materialov, Maşinostroienie, Moskva

Amza, G. (2006), Ultrasunetele. Aplicaţii active, Editura AGIR, Bucuresti, ISBN 973-720-096-9

Bancescu, N. (1995), Studies and Research on Increasing Endurance Rolling Contact with the Unconventional Heat Treatment Applied Tribolayer, PhD Thesis, "Dunarea de Jos" University of Galati, Romania

Biront, V.S. (1977), Primenenie ulitrazvuka pri termiceskoi obrabotke metallov, Ed. Metallurghiia, Moskva

Gherghies, C., (1990), Control of Fine Structure of the Metals with $X$-rays, Ed. Tehnica, Bucuresti, ISBN 973-31-0151-6 